\title{
INDEX TO VOLUME 30
}

$\begin{array}{lllllllllllllll}\text { R. C. BAKER. Small solutions of congruences } & \ldots & \ldots & \ldots & \ldots & \ldots & \ldots & \ldots & \ldots & 164\end{array}$

L. S. BOSANQUET. Convergence and summability factors in a sequence (II) $\quad \ldots \quad \ldots \quad \ldots \quad 255$

BUI AN TON. On a free boundary problem for the equations of tidal motions . . . . $\quad \ldots \quad 222$

A. CANDiotTI. On capitulation in certain $Z_{l}$-extensions of number fields . $\quad \ldots \quad \ldots \quad \ldots \quad$. . 58

D. L. CLEMENTS and C. ROGERS. On the general solution of a linear second order equation with $\begin{array}{lllllllllllll}\text { variable coefficients } & \ldots & \ldots & \ldots & \ldots & \ldots & \ldots & \ldots & \ldots & \ldots & \ldots & \ldots & 94\end{array}$

D. E. DAYKIN and P. FRANKL. On Kruskal's cascades and counting containments in a set of $\begin{array}{llllllllllllllll}\text { subsets } & \ldots & \ldots & \ldots & \ldots & \ldots & \ldots & \ldots & \ldots & \ldots & \ldots & \ldots & \ldots & \ldots & 133\end{array}$

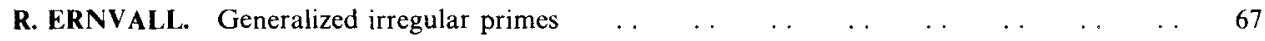

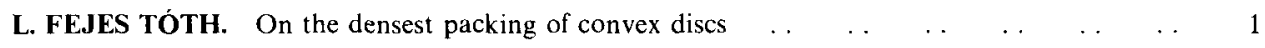

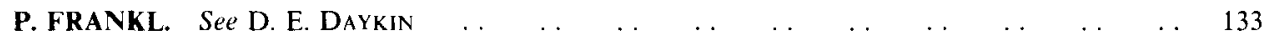

J. GAJJAR and F. T. SMITH. On hypersonic self-induced separation, hydraulic jumps and

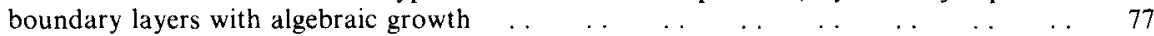

P. GRITZMANN. The toroidal analogue to Eberhard's theorem _. $\quad \ldots \quad \ldots \quad \ldots \quad$. . 274

R. W. HANSELL, J. E. JAYNE and C. A. ROGERS. K-analytic sets $\quad \ldots \quad \ldots \quad$. . $\quad \ldots \quad 189$

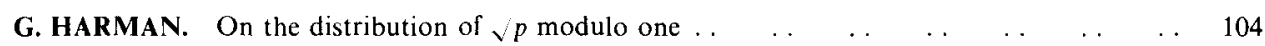

A. HINKKANEN and R. C. VAUGHAN. An analytic inequality $\ldots \quad \ldots \quad \ldots \quad \ldots \quad \ldots \quad 142$

J. G. HINZ. The average order of magnitude of least primitive roots in algebraic number fields 11

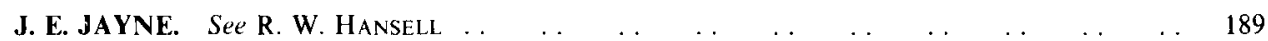

JING YU. Transcendental numbers arising from Drinfeld modules . . . . . . . . . $\quad 61$

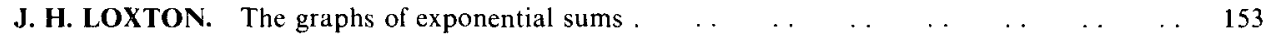

R. OLIVER. Class groups of cyclic $p$-groups $\quad \ldots \quad \begin{array}{llllllllllllll} & \ldots & \ldots & \ldots & \ldots & \ldots & \ldots & \ldots & 26\end{array}$

G. RAMHARTER. Some metrical properties of continued fractions . . . . . . . . $\quad \ldots \quad 117$

C. Rogers. See D. L. Clements $\ldots$.

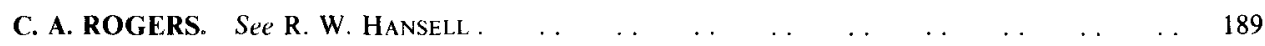

L. A. RUBEL. A counterexample to elimination in systems of algebraic differential equations . . 74

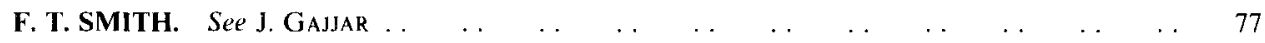

A. SZCZEPANSKI. Aspherical manifolds with $Q$-homology of a sphere $\quad \ldots \quad \ldots \quad \ldots \quad \quad \ldots \quad 291$

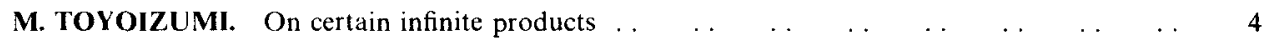

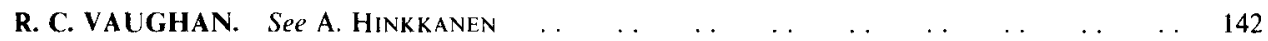

